\title{
Jurnal
}

Manajemen Kesehatan Indonesia

Volume 7

Nomor 1

April 2019

\section{Analisis Kepuasan Pasien Terhadap Kualitas Layanan Poli Gigi di Rumah Sakit Banyumanik Semarang}

\author{
Aulia Ika Pratiwi*, Bagoes Widjanarko ${ }^{* *}$, Sutopo Patria Jati ${ }^{* *}$ \\ "Mahasiswa ARS MIKM Fakultas Kesehatan Masyarakat, Universitas Diponegoro, Semarang \\ ${ }^{* *}$ Fakultas Kesehatan Masyarakat, Universitas Diponegoro, Semarang \\ Email :drgauliaika@gmail.com
}

\section{ABSTRACT}

Based on the medical records of the Banyumanik Hospital, the number of visits in the Banyumanik Hospital dental clinic in 2015 was 766 patients (90\%), increasing in 2016 to 781 (91\%), but decreased in 2017 to 724 patients (85\%) one factor the cause is the quality of service. This study aimed to analyze the effect of quality outpatient services on patient satisfaction in dental polyclinics in hospitals. Banyumanik Semarang. This was quantitative research with cross sectional design. The number of samples in this study were 54 respondents. Research variables were 5 dimensions of service quality. The results of the study showed the dimensions of the quality of outpatient care in dental poly: Real Evidence had a poor result of 68.5, reliability had poor results of 32 respondents $59.3 \%$, poor responsiveness $40.7 \%$, poor guarantees 59.3\%, poor empathy at $55.6 \%$, and less patient satisfaction at $44.4 \%$. In the results of multivariate analysis that the responsiveness variable has the highest significance of 0.039 with the value of $\operatorname{Exp}(B)$ 4,566. The conclusion of this study was that the dimensions of service quality namely Real
Evidence, Responsiveness, and Empathy affect patient satisfaction, while the guarantee does not affect the satisfaction of outpatients in the Dental Polyclinic Hospital. Banyumanik Semarang.

Keywords: Service Quality; Dental Poly; Patient Satisfaction

\section{PENDAHULUAN}

Di indonesia, rumah sakit sebagai salah satu bagian sistem pelayanan kesehatan secara garis besar memberikan pelayanan untuk masyarakat berupa pelayanan kesehatan mencakup pelayanan medik, pelayanan penunjang medik, rehabilitasi medik dan pelayanan perawatan. Pelayanan tersebut dilaksanakan melalui unit gawat darurat, unit rawat jalan dan unit rawat inap. Rumah sakit berupaya memperoleh kepercayaan masyarakat dengan memberikan pelayanan yang efisien dan berkualitas. ${ }^{1}$

Perawatan gigi dan mulut apabila dapat dirawat sedini mungkin dan efisien, sangat membantu dalam meningkatkan derajat kesehatan masyarakat Indonesia pada umumnya. $^{2}$ 
Kualitas pelayanan dan kepuasan pasien mempunyai hubungan yang sangat erat. Pelayanan rumah sakit yang berkualitas akan memberikan kepuasan kepada pasien dan menjadi awal membangun hubungan yang kuat untuk jangka waktu yang panjang (loyalitas). Kualitas layanan menurut Parasuraman memiliki 5 dimensi yaitu bukti fisik (tangible), kehandalan (reliability), daya tanggap (responsiveness), jaminan (assurance), empati (emphaty) ${ }^{3}$

Untuk mewujudkan derajat kesehatan yang setinggi-tingginya bagi masyarakat, diselenggarakan upaya kesehatan yang terpadu dan menyeluruh dalam bentuk upaya kesehatan perseorangan dan upaya kesehatan masyarakat. Upaya kesehatan diselenggarakan dalam bentuk kegiatan dengan pendekatan promotif, preventif, kuratif, dan rehabilitatif yang dilaksanakan secara terpadu, menyeluruh, dan berkesinambungan. ${ }^{4}$

Segala bentuk penyelenggaraan pelayanan secara maksimal yang diberikan dengan segala keunggulan dalam rangka memenuhi kebutuhan konsumen demi memenuhi harapan kepuasan konsumen. Kualitas pelayanan merupakan suatu pernyataan tentang sikap, dan hubungan yang dihasilkan dari perbandingan antara harapan dengan kinerja. ${ }^{8}$

Pengukuran terhadap taraf kualitas pelayanan sangatlah penting terutama untuk meningkatkan kualitas pelayanan dan mendapatkan pelanggan yang setia. Keuntungan yang sebenarnya bukan datang dari pelanggan yang puas saja, melainkan dari pelanggan yang setia. Pemberian kualitas pelayanan yang buruk dan mengecewakan pelanggan merupakan beberapa sebab dari kegagalan. Sehingga, memenuhi keperluan pasien dan berusaha menjaga pelanggan merupakan keutamaan dari organisasi kesehatan. ${ }^{9}$

Rumah Sakit Banyumanik Semarang merupakan salah satu rumah sakit swasta tipe D yang ada di kota Semarang. Rumah Sakit (RS) Banyumanik berkomitmen untuk menyelenggarakan pelayanan kesehatan yang mengedepankan keselamatan pasien dan keamanan pasien dengan selalu menjaga mutu pelayanan.

Berdasarkan data rekam medis RS Banyumanik, jumlah kunjungan di poli gigi RS Banyumanik tahun 2015 sejumlah 766 pasien (90\%), meningkat pada tahun 2016 menjadi 781 (91\%), namun menurun pada tahun 2017 menjadi 724 pasien (85\%).

Berdasarkan hasil wawancara peneliti kepada 10 pasien poli gigi, terdapat keluhan yang terungkap dari pasien mengenai waktu tunggu yang relatif lama. Tujuan penelitian ini adalah untuk menganalisis hubungan kualitas layanan poli gigi terhadap kepuasan pasien di Rumah Sakit Banyumanik. Rumah Sakit Banyumanik berkomitmen untuk menyelenggarakan pelayanan kesehatan yang mengedepankan keselamatan pasien dan keamanan pasien dengan selalu menjaga mutu pelayanan.

\section{METODE PENELITIAN}

Jenis penelitian ini menggunakan metode kuantitatif didukung dengan data kualitatif. Metode kuantitatif yang digunakan adalah non eksperimental, dengan pendekatan cross sectional. Metode pengambilan sampelnya menggunakan purposive sampling, didapatkan sampel penelitian sebesar 54 responden. ${ }^{5}$

Pengolahan data meliputi cleaning, editing, coding, dan entry data. Analisis data disajikan secara univariate (deskriptif). ${ }^{18}$ analisis bivariat dengan uji X (Chi Square). Untuk memperoleh pengaruh variabel bebas terhadap variabel terikat dilakukan uji Regresi Logistik dan untuk mengurangi bias penelitian dilakukan wawancara mendalam dengan triangulasi kepada beberapa petugas penanggung jawab di Rumah Sakit Banyumanik Semarang. 
Penelitan ini telah lolos kaji etik yang diterbitkan oleh Komisi Etik Penelitian Kesehatan FKM Undip dengan No: 226/EA/KEPK-FKM/2018 pada tanggal 27 november 2018.

\section{HASIL DAN PEMBAHASAN}

Hasil dari penelitian ini yaitu pada analisis deskriptif karakteristik responden, kelompok umur terbanyak yaitu berusia 3040 tahun $(42,59 \%)$, dan kelompok umur paling sedikit yaitu 20-30 tahun sebanyak $18,51 \%$ tingkat pendididkan paling banyak adalah SMA yang presentasenya 51.8\% dan yang paling sedikit yaitu tingkat penddidikan SD sebanyak $9,2 \%$ sedangkan untuk jenis kelamin yang paling banyak adalah perempuan sebanyak 55,6\% dan lakilaki sebanyak 44,4\%.

Pada hasil univariat, masing-masing variabel menunjukkan bahwa dimensi kualitas pelayanan pasien rawat jalan di poli gigi pada aspek bukti nyata yang memiliki hasil kurang baik sebesar 37 responden $(68,5 \%)$ sedangkan yang baik sebesar 17 responden $(31,5 \%)$, dimensi kualitas pelayanan pasien rawat jalan di poli gigi dengan kehandalan dan memiliki hasil baik sebesar 22 responden (40,7\%) sedangkan yang kurang baik sebesar 32 responden $(59,3 \%)$, dimensi kualitas pelayanan pasien rawat jalan di poli gigi pada aspek daya tanggap memiliki hasil baik sebesar 32 responden $(59,3 \%)$ sedangkan yang kurang tanggap sebesar 22 responden (40,7\%), dimensi kualitas pelayanan pasien rawat jalan di poli gigi pada aspek jaminan memiliki hasil baik sebesar 22 responden (40,7\%) sedangkan yang kurang baik sebesar 32 responden $(59,3 \%)$, dimensi kualitas pelayanan pasien rawat jalan di poli gigi pada aspek empati memiliki hasil baik sebesar 24 responden (44,4\%) sedangkan yang kurang baik sebesar 30 responden $(55,6 \%)$, dan kepuasan memiliki hasil puas sebesar 30 responden $(55,6 \%)$ sedangkan yang kurang puas sebesar 24 responden $(44,4 \%)$.

Pada hasil analisis bivariat, kualitas layanan terhadap kepuasan pasien pada poli gigi di RS banyumanik Semarang menunjukkan hasil sebagai berikut:

Tabel 1.1 Hasil analisis bivariat

\begin{tabular}{llll}
\hline No & Variable & P value & Kemaknaan \\
\hline $\mathbf{1}$ & Bukti nyata & 0,041 & $\begin{array}{l}\text { Ada } \\
\text { hubungan }\end{array}$ \\
\hline $\mathbf{2}$ & Kehandalan & 0,019 & $\begin{array}{l}\text { Ada } \\
\text { hubungan }\end{array}$ \\
\hline $\mathbf{3}$ & Daya tanggap & 0,008 & $\begin{array}{l}\text { Ada } \\
\text { hubungan }\end{array}$ \\
\hline $\mathbf{4}$ & Jaminan & 0,065 & $\begin{array}{l}\text { Tidak ada } \\
\text { hubungan }\end{array}$ \\
\hline $\mathbf{5}$ & Empati & 0,004 & $\begin{array}{l}\text { Ada } \\
\text { hubungan }\end{array}$ \\
\hline
\end{tabular}

Berdasarkan hasil uji statistik dari tabel 1.1, dapat ditarik kesimpulan bahwa dari kelima dimensi Parasuraman ke empatnya menyatakan ada hubungan antara kualitas layanan dengan kepuasan pasien.

Selanjutnya, dilakukan wawancara mendalam kepada penanggung jawab rumah sakit sebagai verifikasi hasil penelitian dan didapatkan bahwa perlu adanya penambahan petugas medis guna kelancaran proses pelayanan dan perbaikan serta kelengkapan sarana prasarana yang lebih memadai. Selain itu, perlu diadakan peninjauan untuk melakukan beberapa perbaikan agar kualitas layanan RS Banyumanik lebih meningkat dari sebelumnya dengan harapan dapat memenuhi kebutuhan pasien pada saat melakukan pengobatan.

Pada era globalisasi saat ini, tuntutan masyarakat akan kualitas pelayanan kesehatan semakin meningkat. Untuk itu fungsi pelayanan perlu ditingkatkan sehingga dapat memberi kepuasan pada pasien. Kepuasan pasien yaitu keadaan saat keinginan, harapan dan kebutuhan pasien dapat terpenuhi. Semakin baik persepsi pelanggan terhadap kehandalan maka 
kepuasan pasien akan semakin tinggi dimana jika persepsi pasien terhadap kehandalan buruk, maka kepuasan pasien akan semakin rendah. ${ }^{6}$

Perhatian merupakan bagian dari dimensi mutu pelayanan yang berpengaruh terhadap kepuasan pelanggan dalam menggunakan jasa pelayanan. Penelitian Sriwiyanti dalam Saragih S di RS Harapan Pematang Siantar menyatakan bahwa perhatian (empathy) berpengaruh terhadap keputusan pasien untuk menggunakan jasa pelayanan di rumah sakit. Pada dasarnya setiap pasien ingin diperlakukan secara khusus. Dengan demikian rasa simpati dari tenaga medis/paramedik merupakan alat utama untuk memenuhi harapan pasien akan perlakuan istimewa tersebut yang kemudian akan mempengaruhi persepsi kepuasan pasien.

Menurut Kotler dan Keller, kepuasan konsumen dapat diketahui melalui cara cara sebagai berikut. 1. Sistem keluhan dan saran, 2. Survei kepuasan konsumen, 3. Konsumen bayangan (Ghost Shopping), dan 4. Analisis konsumen yang beralih. ${ }^{10}$

Beberapa aspek pelayanan kesehatan yang dapat mempengaruhi persepsi seseorang yang memanfaatkan pelayanan kesehatan adalah kegiatan yang dilakukan dalam pelayanan kesehatan tersebut seperti : faktor dari petugas kesehatan yang melaksanakan pelayanan kesehatan, fasilitas yang digunakan dalam pelayanan pengobatan dan perawatan, pelayanan medik dan penunjang medik mulai dari penegakan diagnosa sampai tindakan pengobatan dan perawatan serta pelayanan administrasi. Untuk mengetahui seberapa jauh pelayanan kesehatan yang dilakukan kepada masyarakat, maka dibutuhkan penilaian dari sisi konsumen yaitu dari aspek kepuasan pasien, terutama terhadap pelayanan kuratif. Bila pelayanan kesehatan baik biasanya pasien akan puas dan tetap memilih sarana pelayanan tersebut sebagai tempat berobat. 11

Faktor utama yang mempengaruhi kulitas layanan adalah layanan yang diharapkan pelanggan (expected service) dan persepsi terhadap layanan (perceived service). Apabila perceived service sesuai dengan expected service, maka kualitas layanan yang bersangkutan akan dinilai baik atau positif. Jika perceived sercivice melebihi expected service, maka kualitas layanan yang dipersepsikan sebagai kualitas ideal. Sebaliknya apabila perceived service lebih jelek dibandingkan expected service, maka kualitas layanan dipersepsikan negatif atau buruk. ${ }^{7}$

Penelitian yang dilakukan oleh Inna sholihati dkk tahun 2013 dengan menggunakan uji beda (t-test dan Anova) menyatakan bahwa persepsi kepuasan pasien terhadap kualitas pelayanan yang ditinjau dari 5 dimensi yang menyatakan sangat puas sebesar $77 \%$ dan yang menyatakan puas $23 \%$. Faktor dimensi bukti langsung (tangible) merupakan faktor paling utama yang dapat meningkatkan kepuasan pasien.

Pelayanan yang diberikan petugas kesehatan merupakan salah satu penunjang keberhasilan pelayanan kepada pasien yang sedang menjalani pengobatan. Sikap yang ditunjukkan dengan tingkah laku hendaknya memenuhi norma yang dikehendaki oleh masyarakat terutama oleh penderita dan keluarga pasien.

Penelitian yang dilakukan oleh Gatu Shanti Aji Dewi pada tahun 2010 menunjukkan bahwa kepuasan pasien berdasarkan dimensi daya tanggap sebesar 46,30\%, hal ini disebabkan karena pasien merasa kurang puas terhadap kecepatan tenaga medis pada saat pasien membutuhkan dan pemberian informasi yang kurang jelas. Hubungan daya tanggap dengan kepuasan pasien ialah daya tanggap mempunyai pengaruh positif dan signifikan terhadap kepuasan pasien. Semakin baik persepsi 
pelanggan terhadap daya tanggap maka kepuasan pasien akan semakin tinggi, dan jika persepsi pasien terhadap daya tanggap buruk, maka kepuasan pasien akan semakin rendah.

Pentingnya dimensi perhatian dalam memberikan pelayanan yang bermutu. Hal ini sejalan dengan penelitian Rattoe pada tahun 2013 mengenai hubungan antara mutu pelayanan dengan keputusan kunjungan ulang di RSU Bethesda Tomohon yang mendapatkan bahwa variabel perhatian sangat dominan pengaruhnya terhadap kepuasan pasien.

\section{KESIMPULAN}

Berdasarkan hasil penelitian didapatkan bahwa 5 dimensi kualitas layanan yaitu bukti nyata, kehandalan, daya tanggap, jaminan dan empati memiliki hasil rata - rata dibawah $50 \%$ dan perlu ditingkatkan lagi kualitas layanan agar dapat membuat pasien nyaman dan puas. Kedua Lebih dari $50 \%$ pasien merasa puas akan pelayanan yang Rumah Sakit Banyumanik berikan. Ketiga, kualitas layanan rawat jalan berhubungan terhadap kepuasan pasien pada RS Banyumanik Semarang. Keempat, kualitas layanan di Rumah Sakit Banyumanik masih kurang dan perlu ditingkatkan guna memperbaiki mutu pelayanan dan meningkatkan kepuasan pasien. Kelima, Rumah Sakit Banyumanik akan memperbaiki kinerja petugas dan mengupayakan untuk menambah jumlah tenaga medis guna mencapai hasil yang lebih baik.

Saran yang dianjurkan, sebaiknya dapat menambahkan petugas kesehatan baik dokter gigi dan perawat sehingga pelayanan dapat lebih maksimal, Diupayakan agar mendapatkan pelatihan mengenai pelayanan kepuasan pasien untuk para petugas di Rumah Sakit Banyumanik Semarang dan memperbaiki sistem pelayanan rumah sakit khususnya poli gigi agar pasien dapat merasa puas dalam berobat.

\section{DAFTAR PUSTAKA}

1. Supartiningsih, Solichah. Kualitas Pelayanan dan Kepuasan Pasien di Rumah Sakit : Kasus pada Pasien Rawat Jalan. Jurnal Medicoeticolega; 1 dan Manajemen Rumah Sakit. Volume 6; No.1; Hal 9-15. Januari 2017.

2. Rundungan, Ria O. Dkk. Analisis Kinerja Petugas Kesehatan Gigi Terhadap Pelayanan Kesehatan Gigi dan Mulut di poliklinik Gigi RSUD Datoe Binangkang Kabupaten Bolaang Mongondow. JIKMU, Vol 5. No.2. April 2015

3. Khumayrah, ummi. Kualitas Pelayanan Rumah Sakit Umum Daerah Daya (Perawatan Interna) Makasar. Univrsitas Hasanuddin. 2015

4. Budiarto. Kualitas Pelayanan Kesehatan Puskesmas di Kecamatan Enrekang Kabupaten Enrekang. Universitas Hasanuddin. 2015

5. Khusaini, Ahmad. Analisis Kualitas pelayanan Terhadap Kepuasan Konsumen di SPA Club Arena Yogyakarta. Universitas Negeri Yogyakarta. 2016.

6. Almasri, M. Nazar. Manajemen Sumber Daya Manusia : Imlementasi dalam Pendidikan Islam. Jurnal Penelitian Sosial Keagamaan. Volume 19; No.2 ; Juli-Desember 2016.

7. Fandy Tjiptono,. Service Management Mewujudkan Layanan Prima. Edisi II. Yogyakarta. 2012

8. Nani, Supardi, dan Wolok, Tineke. Analisis Kepuasan Pelayanan Terhadap Kepuasan Pelanggan Pada PT Bank Sinar Mas Cabang Gorontalo. Universitas Negeri Gorontalo. 2014.

9. Setyaningsih, Ira. Analisis Kualitas Pelayanan Rumah Sakit Terhadap Pasien Menggunakan Pendekatan Lean 
Servperf (Lean Service dan Service Performance). Jurnal Spektrum Industri. Volume 11. No.2. 2013.

10. Algifari. Mengukur Kualitas Layanan dengan Indeks Kepuasan, Metode Importance-Performance Analysis (IPA) dan Model kano. Cetakan pertama. Januari 2016.

11. Jalimun, yaya priatna. Dkk. Kepuasan Pasien Di Balai Pengobatan gigi (BPG) Puskesmas Kahuripan Kota Tasikmalaya. Jurnal Kesehatan komunitas indonesia. Vol. 10. No 1 Maret 2014. 